\title{
Heat-exchange units with porous inserts
}

\author{
Oleg Stepanov ${ }^{1}$, Boris Aksenov ${ }^{1}$, Natalia Rydalina ${ }^{1, *}$, and Elena Antonova ${ }^{1}$ \\ ${ }^{1}$ Industrial University of Tyumen, Tyumen, Russia
}

\begin{abstract}
Currently, porous metals are not used in heat supply systems. Usage of porous materials in heat exchangers increases the heat transfer intensity and makes the heat exchangers more compact. An experimental setup consisting of two circuits was developed in order to study the influence of porous metals on heat transfer intensity. In the first circuit the hot coolant is water, which flows through narrow tubes inside the porous metal. In the second circuit the cold coolant is freon. The purpose of the study is to obtain experimental confirmation of the hypothesis of an increase in the heat transfer intensity when using porous metals. To achieve this goal, experiments were carried out, which showed the increased heat transfer intensity. The standard methods for calculating heat exchangers cannot be applied in this case as the inner pores' surface is unknown. A mathematical model was compiled allowing engineering calculations for the heat exchangers of this type. The hot water temperature inside the heat exchanger is determined analytically. The resulting equation allows us to determine the cooling degree of the first coolant, i.e. hot water. The obtained deviations between experimental and analytical data are within the acceptable limits, which indicates the reliability of the proposed model.
\end{abstract}

\section{Introduction}

One of the main tasks in production of modern heat transfer equipment is to achieve increased heat transfer intensity. One of the promising ways here is the use of porous metals in heat exchangers.

Heat exchangers with porous metals can be obtained in various design solutions. There are plate heat exchangers, in which the inter-plate channels for coolant motion are filled with porous metal inserts with a high specific area of the inner frame surface and small equivalent diameters of the internal channels, providing a high rate of heat exchange of the working medium. The proposed design significantly increases heat transfer [1-3].

Porous-compact heat exchangers are used, the operation principle of which is based on intensification of heat transfer processes by introducing a porous filler made of materials with high thermal conductivity into the circuit channels. A highly porous material with a variable relative thickness of the porous material is used for filling in one of the most effective designs of such heat exchangers. The housing cross section is cylindrical round or oval. [4-8]

There are original designs of evaporation elements, which are intended to cool bodies in various fields of industry. The evaporation element is made in a form of a three-layer wall adjacent to the heat transfer surface with boundary and middle layers having various porosities. The boundary layers are made of porous metal with an average porosity of about 0.5 , and the middle layer having low porosity of about 0.2-0.25 [9-18].

A special setup for investigation the efficiency of usage of such materials was developed and created at Tyumen Industrial University.

The object of research is the heat transfer process in heat exchangers of the "liquid-gas" type with and without phase transition of the coolant.

The theoretical basis for the creation of a "water-gas" type heat exchanger with a phase transition of the coolant is the research of I. Popov and other authors [19, 20].

In this paper, we consider the design of a heat exchanger in which porous aluminum is used. The coolant (freon) flows through the pores, the second coolant (cooled water) flows through the pipes which are inside the porous metal.

The heat exchanger is an assembly of 19 copper tubes for water flow, that are covered by four cylindrical inserts of porous aluminum. There are three heat exchangers in total. In the first heat exchanger, the inserts' porosity is 0.4903 , in the second heat exchanger the inserts' porosity is 0.4865 , and in the third heat exchanger the inserts' porosity is 0.4739 . The inner part of the heat exchanger with porous inserts is shown in Fig. 1.

\footnotetext{
* Corresponding author: rydalinanv@tyuiu.ru
} 


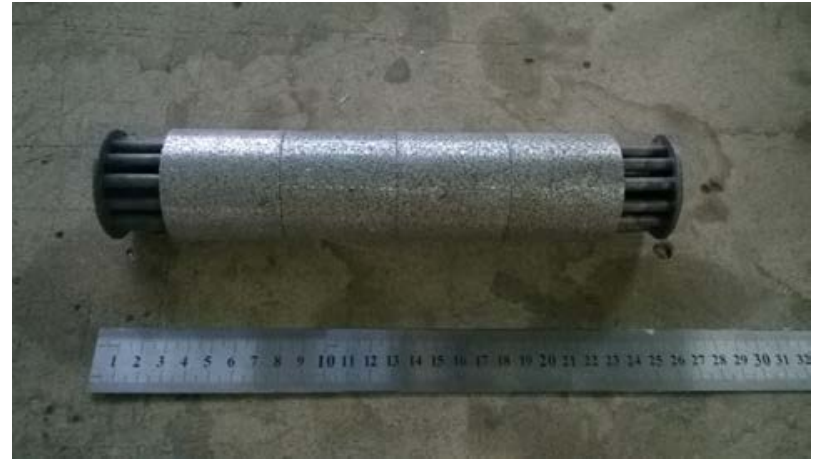

Fig.1. Inserts made of porous aluminum

Porous inserts are cylinders of porous aluminum with a height of $50 \mathrm{~mm}$ and a diameter of $49 \mathrm{~mm}$. Each insert has 19 holes with a $6 \mathrm{~mm}$ diameter, for tubes through which water moves. freon flows through the pores of the insert.

The experimental setup consists of two circuits. The first circuit with water is equipped with a pump, a boiler for water heating, as well as a measuring and computing complex, which allows tracking the water temperature change and monitoring the mass flow rate with a time resolution of $3 \mathrm{~s}$. The second circuit is the evaporation part, into which R404a freon is poured.

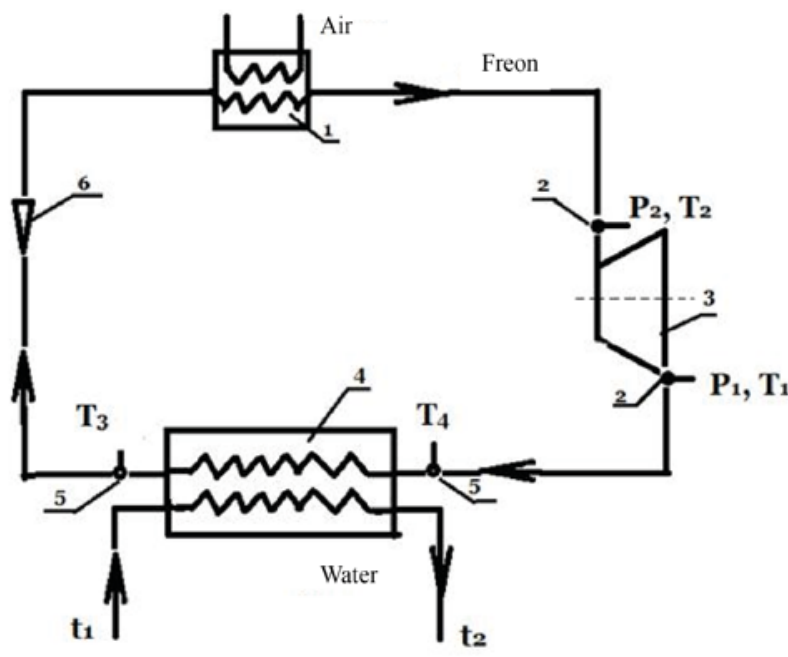

Fig.2. Block diagram of the freon circuit of the setup.

1 - Condenser; 2 - Thermo-manometer; 3 - Compressor; 4 Evaporator; 5 - Temperature sensor; 6 - Throttle.

The freon circuit (Fig. 2) includes sensors for measuring temperature and freon pressure at the inlet and outlet of the compressor.

The experiments were carried out for each of the three available heat exchangers at a constant water flow. Water and freon temperatures at the inlet and outlet of the heat exchanger were measured. Water consumption was measured by a control device. In order to exclude random errors, for each change in flow rate, the readings of the temperature change were taken 10 times. As a result, an array of data was obtained, which makes it possible to estimate the heat exchange intensity. The results of the performed cycle of measurements indicate the appropriateness of porous metals usage in heat exchange equipment. [21]
The task is to develop a mathematical model that allows determining the coolant temperature in any cross section of the heat exchanger. The standard methods for calculating heat exchangers cannot be applied in this case as the inner pores' surface is unknown. A simplified mathematical model of such a heat exchanger was compiled, that allows obtaining a solution in an analytical form convenient for engineering calculations. Numerical calculations based on this model were compared with experimental data. The experimental and calculated values coincide within the experimental error.

\section{Methods}

We consider a porous cylinder (porous insert) made of aluminum with a constant thermal conductivity coefficient $\lambda c$. The cylinder is well insulated, so we assume that there is no heat exchange with the external environment through its surface. There are several copper tubes inside the porous cylinder, through which cooled water flows with inlet temperature $t_{\text {in }}$ (Fig. 3 ).

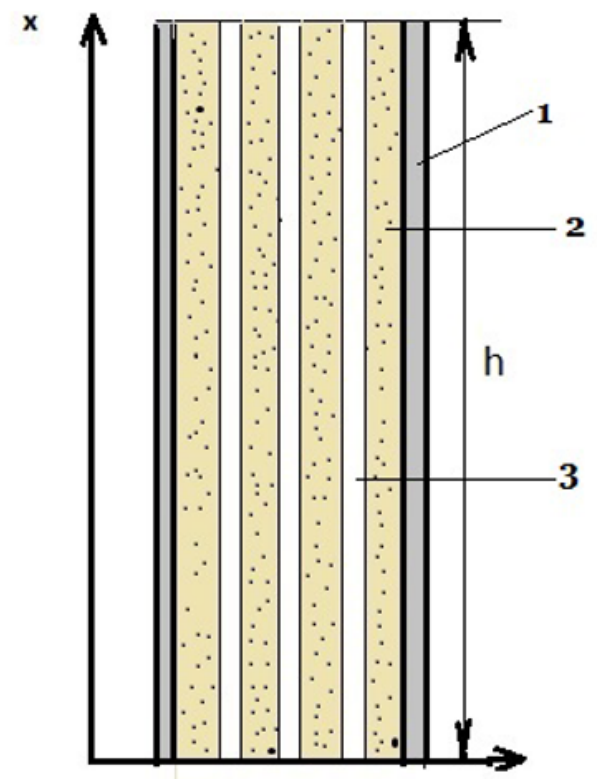

Fig.3. Porous cylinder with tubes:

1 - Heat-insulating material; 2 - Porous metal; 3 - Copper tube.

Freon is continuously supplied from the bottom to the top with a constant specific mass flow rate Gc.

Water from a certain tank enters the tubes from top to bottom (counterflow circuit) with a constant specific mass flow rate $\mathrm{Gw}$, and then returns to the tank again. Thus, the process is cyclical. The time during which the volume of water equal to the internal volume of all tubes passes through the heat exchanger is called the cycle time $\tau c$. The calculation is carried out for each cycle separately. During the cycle, the water is cooled and at the outlet its temperature is $t_{\text {out }}$ (found by calculation). The water in the tank is also cooled, so in the next cycle the value $t_{\text {in }}$ will be different. It is also found by calculation. Further, everything is repeated many times. The task is to find the relationship between $t_{\text {out }}$ and the 
total operating time of the setup and compare the calculated data with the experimental ones.

The inner surface area of tubes $\mathrm{S}$ is known. The volume of the porous insert $\mathrm{V}_{\text {por }}$ is known. The freon temperature at the inlet and outlet $t(0)=t_{c 1}$ and $t(h)=t_{c 2}$, and specific mass flow rates of freon and water $\left(G_{c}\right.$ and $G_{w}$ ) are measured during the experiment.

Heat capacities of freon $\mathrm{c}_{\mathrm{pc}}$ and water $\mathrm{c}_{\mathrm{pw}}$ are known.

The inserts' porosity $\mathrm{p}$ is considered as the ratio of the pore volume to the total volume of the material. The porosity is considered uniform, therefore, on a unit surface normal to the direction of gas flow, the cross section for the gas passage is $\mathrm{f}_{\text {liq }}=\mathrm{p}$, and the cross section of the solid shell involved in thermal conductivity is fc $=1-\mathrm{f}_{\text {liq }}=1$-p. It should also be noted that if the specific mass flow rate of freon is $G_{c}$, then the mass flow rate inside the plate will be $\mathrm{Gc} / \mathrm{p}$.

For the one-dimensional problem of cooling a porous body, the equation is known:

$$
\frac{d^{2} t}{d x^{2}}-A \frac{d t}{d x}=0
$$

where $\frac{G_{c} \cdot C_{p c}}{\lambda_{c}(1-p)}=A$.

In deriving this equation, an assumption was made that all heat transfer inside the porous body is performed due to thermal conductivity through the solid phase and that the temperatures of the solid and the coolant are almost the same at any point in the porous structure. If we accept this assumption, then equation (1) can describe the heat transfer process in a homogeneous porous insert, that is, without tubes with water (Fig. 3). In this case, the temperature field can be considered onedimensional, taking into account thermal insulation.

In the presence of tubes with water, the temperature field becomes two-dimensional and equation (1) cannot be applied.

It is proposed to complete this equation with a function of distributed heat sources (sinks), which with some error describes the process of heat transfer from a porous material through the walls of copper pipes to water.

$$
q=\frac{\alpha \cdot\left(t_{w}-t\right) \cdot S}{\lambda_{w} \cdot V_{p o r}}
$$

As a result we obtain the following equation:

$$
\frac{d^{2} t}{d x^{2}}-A \frac{d t}{d x}+\frac{\alpha \cdot\left(t_{w}-t\right) \cdot S}{\lambda_{w} \cdot V_{p o r}}=0
$$

where $\mathrm{V}_{\text {por }}$ is the volume of the porous inserts, $\alpha$ is the heat transfer coefficient from copper wall to water, $t_{w}$ is water temperature for the given value of $x$.

The uniqueness condition is:

$$
0 \leq \mathrm{x} \leq \mathrm{h}, \mathrm{t}(0)=\mathrm{t}_{\mathrm{c} 1}, \mathrm{t}(\mathrm{h})=\mathrm{t}_{\mathrm{c} 2}
$$

When deriving equation (2), the thermal resistance of the copper walls was neglected.
The solution is greatly simplified if we assume that $\mathrm{t}_{\mathrm{w}}-\mathrm{t}=$ const. This assumption is quite acceptable for $\mathrm{a}$ small insertion height $h$ and when using a counterflow circuit. The value $\alpha$ is found from the equations of convective heat exchange in pipes.

$$
\text { We denote } \frac{\alpha \cdot\left(t_{w}-t\right) \cdot S}{\lambda_{w} \cdot V_{\text {por }}}=B \text {, and }
$$

the expression (3) takes the form:

$$
\frac{d^{2} t}{d x^{2}}-A \frac{d t}{d x}+B=0 \text {. }
$$

The boundary problem (3-4) is solved by standard methods and the function of changing the temperature of the porous metal of the heat exchanger along the $\mathrm{x}$ axis is obtained:

$$
t=t_{c 1}+\frac{B}{A} x+\left(e^{A x}-1\right) \cdot \frac{t_{c 2}-t_{c 1}-\frac{B}{A} h}{e^{A h}-1}
$$

We differentiate the obtained temperature function with respect to the variable $\mathrm{x}$ :

$$
\frac{d t}{d x}=\frac{B}{A} x+\frac{\left(t_{c 2}-t_{c 1}\right) \cdot A-B \cdot h}{e^{A h}-1} \cdot e^{A x}
$$

Knowing function (7), we obtain the formula for the heat flux density:

$$
q=-\lambda_{c} \cdot(1-p) \cdot\left(\frac{B}{A} x+\frac{\left(t_{c 2}-t_{c 1}\right) \cdot A-A \cdot h}{e^{A h}-1} \cdot e^{A x}\right)
$$

The value $\mathrm{Q}(\mathrm{h})-\mathrm{Q}(0)$, where $\mathrm{Q}$ is the amount of heat, in the absence of heat losses, is equal to the heat transferred from water to freon. Further we find the outlet water temperature.

The results are valid for one complete cycle.

\section{Results and Discussion}

It is advantageous to carry out experiments in parallel with performing calculations using the described technique. The fact is that in the experiment, water is pumped continuously, and the operating time is conditionally divided into cycles in the mathematical model. With the introduction of this concept, it becomes possible to determine the amount of heat that flowing water loses per cycle. Based on this, it becomes possible to obtain the temperature dependence on time for a given mass of water that is pumped through a heat exchanger.

The experimental results made it possible to analyze the degree of water cooling for various periods of time using a material with a different coefficient of porosity.

Figure 4 presents the experimental results, which almost coincide with the results of calculations using formulas (2)-(5). This high accuracy of calculations is partially explained by the fact that the boundary conditions are taken from the same experiments. If boundary conditions are determined before experiments, for general reasons, then the error will be greater. The experiments were carried out for the following main parameters: the porous sample diameter $\mathrm{d}=0.049 \mathrm{~m}$; the total length of the porous insert $\mathrm{h}=0.2 \mathrm{~m}$; number of 
tubes $n=19$; the inner diameter of the tubes $d=0.004 \mathrm{~m}$; heat capacity of water $c_{p}=4187 \mathrm{~J} / \mathrm{kg} \cdot \mathrm{K}$; thermal conductivity of aluminum $\lambda \mathrm{s}=209.3 \mathrm{~W} / \mathrm{m} \cdot \mathrm{K}$.

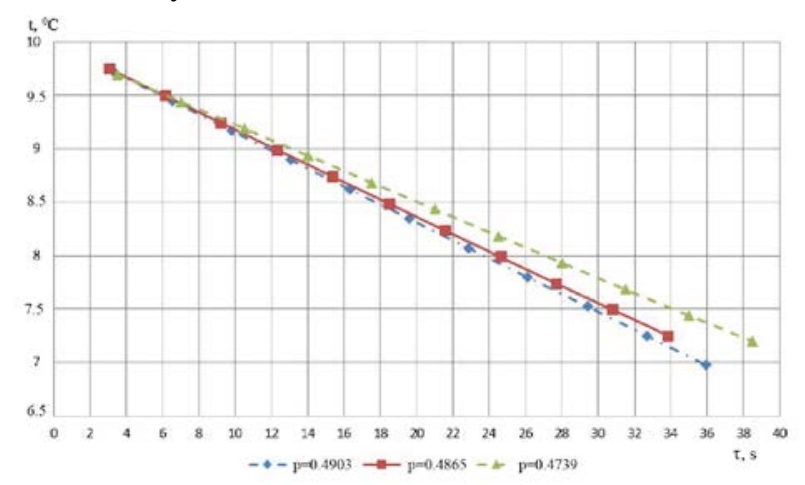

Fig. 4. The change in time of the degree of cooling of the coolant at the outlet of the heat exchanger.

The graph shows that the most intense water cooling occurs in the heat exchanger with inserts of a porous material having the highest porosity coefficient.

\section{Conclusions}

Based on the performed experiments and calculations, the following conclusions can be drawn:

1. The resulting equation allows one to determine the temperature change of the porous material and the hot fluid in any section of the heat exchanger.

2. In a heat exchanger with a porous metal, the heat transfer intensity increases with increasing the porosity coefficient.

3. On the basis of a laboratory setup, it becomes possible to create a heat exchanger that can be used in heat supply systems.

\section{References}

1. S. Rashidi, M. Kashefi, K. Kim, Samimi- O. Abianeh, Potentials of porous materials for energy management in heat exchangers - A comprehensive review. Applied Energy 243, 206-232 (2019).

2. W. Tan, L. Saw, H. Thiam, J. Xuan, Z. Cai, M. Yew, Overview of porous media/metal foam application in fuel cells and solar power systems. Renewable and Sustainable Energy Reviews 96, 181-197 (2018).

3. M. Sarkar, K. Velusamy, P. Munshi, O.P. Singh, Analysis of flow and heat transfer through a partially blocked fuel subassembly of fast breeder reactor. Progress in Nuclear Energy 118, 103142 (2020)

4. K. Anirudh, S. Dhinakaran, Performance improvement of a flat-plate solar collector by inserting intermittent porous blocks. Renewable Energy 145, 428-441, (2020)

5. A. Robone, S. Kuruneru, M. Islam, S. Saha, A macroscopic particle modelling approach for nonisothermal solid-gas and solid-liquid flows through porous media. Applied Thermal Engineering 162, 114232 (2019)

6. C. Soto, C. García-Rosales, J. Echeberria, E. Platacis, A. Shisko, F. Muktepavela, M. Malo, Characterization and thermomechanical assessment of a SiC-sandwich material for Flow Channel Inserts in DCLL blankets. Fusion Engineering and Design 146, 1983-1987 (2019)

7. C. Soto, C. García-Rosales, J. Echeberria, E. Platacis, A. Shisko, F. Muktepavela, M. Malo, T. Hernández, Numerical study on latent thermal energy storage systems with aluminum foam in local thermal equilibrium. Applied Thermal Engineering 159, 113980 (2019)

8. A. Vikulin, N. Yaroslavtsev, V. Zemlyanaya, Investigation into Transpiration Cooling of Blades in High-Temperature Gas Turbines. Thermal Engineering 66, 397-401 (2019)

9. X. Yang, J. Yu, Z. Guo, L. Jin, Y.-L. He, Role of porous metal foam on the heat transfer enhancement for a thermal energy storage tube. Applied Energy 239, 142-156 (2019)

10. A. Korsun, I. Merinov, V. Kharitonov, M. Bayaskhalanov, V. Chudanov, A. Aksenova, V. Pervichko, Numerical Simulation of ThermalHydraulic Processes in Liquid-Metal Cooled Fuel Assemblies in the Anisotropic Porous Body Approximation. Thermal Engineering 66, 225-234 (2019)

11. M. Sarkar, K. Velusamy, P. Munshi, O. Singh, Analysis of flow and heat transfer through a partially blocked fuel subassembly of fast breeder reactor. Progress in Nuclear Energy 118, 103142 (2020)

12. X. Lu, Y. Zhao, Effect of flow regime on convective heat transfer in porous copper manufactured by lost carbonate sintering. International Journal of Heat and Fluid Flow 80, 108482 (2019)

13. O. Stepanov, N. Rydalina,. E. Antonova , I. Akhmetova, P. Zunino, The possibility of increasing the operating efficiency of gas turbines at compressor stations of main gas pipelines. International Journal of Civil Engineering and Technology 10(2), 2130-2137 (2019)

14. M. Liu, Z. Cui, Y. Li, Modeling and Simulation of Porosity in Spray Deposition. Metallurgical and Materials Transactions B: Process Metallurgy and Materials Processing Science 50, 1908-1920 (2019)

15. B. Buonomo, H. Celik, D. Ercole, O. Manca, M. Mobedi, Numerical study on latent thermal energy storage systems with aluminum foam in local thermal equilibrium. Applied Thermal Engineering 159, 113980 (2019)

16. K. Venkateshwar, S. Ebadi, H. Simha, S. Mahmud, Influence of pore density and porosity on the melting process of bio-based nano-phase change materials inside open-cell metal foam. Journal of Thermal Science and Engineering Applications 11, 041004 (2019) 
17. J. Qu, Q. Sun, H. Wang, D. Zhang, J. Yuan, Performance characteristics of flat-plate oscillating heat pipe with porous metal-foam wicks. International Journal of Heat and Mass Transfer 137, 20-30 (2019)

18. A. Akinshilo, Mixed convective heat transfer analysis of MHD fluid flowing through an electrically conducting and non-conducting walls of a vertical micro-channel considering radiation effect. Applied Thermal Engineering 156, 506-513 (2019)

19. I. Popov: Hydrodynamics and heat exchange in porous heat exchange elements and apparatus. Center of innovative technologies Kazan (2007).

20. Y. Gortyshov: Thermal-Hydraulic efficiency of perspective methods of heat transfer intensification in heat exchange equipment channels. Center of innovative technologies. Kazan (2009).

21. V. Davletbaev, N. Rydalina, E. Antonova: MATEC Web of Conferences 245, 07002 (2018). 